\title{
USO Y GOCE DE LA PROPIEDAD \\ URBANA
}

\author{
Guillermo Bruna Contreras \\ Profesor de Derecho Constitucional \\ Facultad de Derecho - Universidad Católica de Chile
}

\section{SUMARIO}

Introducción. I. Estatuto constitucional del uso y goce de la propiedad urbana. II. La ley general de urbanismo y construcciones. III. Uso del suelo y construcciones.

\section{INTRODUCGION}

Recientes aprobaciones de Planes Reguladores y sus continuas modificaciones, con sus consecuencias en cambios de valor de las propiedades, hacen pensar si las decisiones de autoridades administrativas son racionales o caprichosas, están bien o mal inspiradas, son justas o injustas.

Frente a la garantía constitucional del derecho de propiedad, base de nuestro orden jurídico-económico, ¿se estará actuando bien? y frente al valor de la justicia ¿se estará siendo justos?. Desde el punto de vista urbanístico ¿se irá en la dirección correcta?.

EI respeto universal por los derechos humanos, un creciente acostumbramiento a limitar el poder estatal para hacer más libres a los individuos, y la necesidad de resguardar a inversionistas nacionales y extranjeros, debe llevarnos a revisar los criterios y las rutinas que nos dominaron por muchos años.

Por otro lado, la necesidad de preservar el medio ambiente y de hacer más humanas y gratas nuestras ciudades, exige imponer condiciones ordenadas y racionales en su crecimiento y expansión, compatibilizando los intereses económicos y espirituales privados del propietario con los colectivos de la comunidad.

Precisar el límite de lo privado y de lo público, de lo particular y de lo colectivo, de la oposición entre el bien personal y el común, constituye una tarea delicada y de nunca acabar, que corresponde al arte político. 
Para comenzar quisiera precisar las normas, bases fundamentales, principios y garantías que deben presidir la legislación y la acción concreta de los encargados de aplicarla.

En primer término debo decir que, sea en lo legislativo o en lo administrativo o municipal, la finalidad del Estado es promover el bien común con pleno respeto a los derechos naturales del hombre y garantías constitucionales (artículo $1^{\circ}$ inciso $4^{\circ}$ de la Constitución Política de la República, de 1980). Bien común es el bien de todos, no de la mayoría ni de la minoría, no de unos ni de ciertos grupos, de todos, sin excepción. Bien que debe buscarse, que debe tratar de lograrse, sin que ninguno ni unos pocos, ni muchos, soporten el peso o el precio de su consecución. Todos se benefician y todos soportan su costo, sin excepciones ni discriminaciones. No podría uno pagar el precio para beneficiar a 99 , aunque matemáticamente ello sea conveniente.

En segundo término, debo recordar que uno de los deberes del Estado es dar protección a la población (a toda, no a algunos), como también es su deber promover la integración armónica de todos los sectores de la Nación (pobladores, industriales, comerciantes, profesionales, entre otros) y asegurar el derecho de (todas) las personas a participar con igualdad de oportunidades en la vida nacional ( $\sin$ discriminación) (artículo $1^{\circ}$ inciso $5^{\circ}$ ).

En tercer lugar, no debemos olvidar que el ejercicio de la soberanía - que lo realiza cada uno de los órganos del Estado y cada uno de sus integrantes - sea en el orden legislativo, administrativo o municipal, por ejemplo, reconoce como limitación el respeto a los derechos esenciales que emanan de la naturaleza humana. Esto significa, en concreto, que ninguna acción del Estado, encaminada por cierto hacia el bien común, puede hacerse con lesión de un derecho esencial de una persona, afirmación que guarda completa armonía con lo dicho en primer término. Adicionalmente, debemos considerar que, no sólo el respeto a los derechos de las personas es un límite a la acción del Estado, sino que es un deber de sus órganos respetarlos y promover tales derechos, como bien lo dice el inciso $2^{2}$ del artículo $5^{\circ}$ de la misma Constitución.

Enseguida hay dos principios más que respetar, los que no por ser más antiguos en nuestro Orden Constitucional son menos importantes. Me refiero al principio de subordinación constitucional, que obliga a los órganos del Estado, a sus titulares o integrantes, como también a toda persona, institución o grupo, a someter su acción a la Constitución, a sus preceptos, y a las normas dictadas conforme a ella (artículo 6º y el principio de legalidad, que prohibe a toda autoridad, persona o grupo, atribuirse un 
derecho o facultad que no le haya sido conferido expresamente en virtud de la Constitución o las leyes, ni aun a pretexto de circunstancias extraordinarias (artículo $7^{\circ}$ ).

Descritos los márgenes que podríamos llamar fundamentales, generales o macros, dentro de los cuales puede moverse una autoridad que quiera, en busca del bien común, organizar la ciudad y fijar un Plan Regulador, veamos ahora los límites específicos o micros, respecto de la propiedad y el medio ambiente.

Los Planes Reguladores comunales constituyen el medio a través del cual se realiza la planificación urbana comunal, y ésta promueve el desarrollo armónico del territorio comunal, en especial de sus centros poblados (artículos 30 y 31 de la Ley General de Urbanismo y Construcciones, DFL (Minvu) № 458, de 1976).

El contenido de un Plan se refiere al uso del suelo o zonificación, localización del equipamiento comunitario, estacionamientos, jerarquización de la estructura vial, fijación de límites urbanos, densidades y determinación de prioridades en la urbanización de terrenos para la expansión de la ciudad y demás aspectos urbanísticos (artículo 41 de la misma Ley).

Como puede observarse, en un Plan Regulador se mezclan el uso y regulación de bienes públicos y de bienes privados. Son estos últimos los que interesan a este trabajo y a ellos me limitaré. Dice el artículo 57 de la citada Ley que: "El uso del suelo urbano en las áreas urbanas se regirá por lo dispuesto en los planes reguladores, y las construcciones que se levanten en los terrenos serán concordantes con dicho propósito".

Suelo y construcciones urbanas dependen, por lo tanto, de lo que dispongan los Planes Reguladores. Dicho de otra manera, el uso y goce de los inmuebles urbanos dependen de los Planes Reguladores. La propiedad raíz urbana, los inmuebles urbanos, están entregados a lo que digan los Planes Reguladores.

Como la propiedad raíz sigue siendo uno de los objetos más valiosos del patrimonio de las personas, resulta muy necesario estudiar si su estatuto jurídico está siendo respetado o no por estos Planes Reguladores.

\section{ESTATUTO CONSTITUCIONAL DEL USO Y GOCE DE LA PROPIEDAD URBANA}

Como se trata tan sólo de analizar el uso y goce de la propiedad urbana, regulados por un Plan Regulador, me limitaré a considerar el estatuto consti- 
tucional en esos aspectos, sin abordar ni la adquisición ni la pérdida de la propiedad.

Dice la Constitución que asegura a todas las personas "el derecho de propiedad en sus diversas especies sobre toda clase de bienes corporales o incorporales" (artículo 19 № 24 inciso $1^{\circ}$ ), de modo que la propiedad raíz urbana se encuentra protegida constitucionalmente, sin duda alguna.

La Constitución encarga a la ley establecer el modo de usar y gozar de la propiedad, pero ese encargo lo expresa de un modo especial, pues no sólo faculta a la ley para hacerlo, sino que lo hace reservándole a ella, en forma exclusiva, tal facultad, es decir, prohibiendo a toda otra norma o a toda otra autoridad que lo haga (so pena de nulidad, artículo 7º). Dice: "sólo la ley puede...", de modo que un reglamento, un decreto, una ordenanza, un acuerdo municipal (y sus respectivos autores), si no están aplicando una ley que haya establecido el modo de usar o gozar de la propiedad, o lo están contradiciendo, no podrían hacerlo. La norma habilitante es la ley y nada más o nada menos que la ley.

¿Qué más puede hacer la ley respecto de la propiedad urbana? Puede establecer las limitaciones y obligaciones que deriven de la función social que debe cumplir la propiedad urbana.

¿Es soberana la ley para establecer los modos de usary de gozar la propiedad, o para establecer limitaciones y obligaciones a la misma? La propia Constitución se preocupa de respondernos a estas preguntas. En el mismo № 24 del artículo 19 nos garantiza que "nadie puede, en caso alguno, ser privado... de algunos de los atributos o facultades esenciales del dominio...". De modo que, respecto al uso y goce de la propiedad, la ley puede establecerlos de tal modo que no se llegue, en el hecho y en cada caso particular, a una privación de tales uso y goce, que son facultades esenciales del dominio. Deberá existir una prudencia, una ponderación que, al fijar y al explicar cómo se usará o gozará de la propiedad, no se esté siendo tan exagerado que, por dificultades o requisitos, se llegue a privar al propietario del uso y goce de su propiedad. Lo mismo vale para las limitaciones u obligaciones, las que deben ser apropiadas, proporcionadas, parciales o temporales, que sigan permitiendo el uso y goce normales, aunque con ciertas dificultades, sin llegar a su privación o imposibilidad. Además, en este caso de las limitaciones y obligaciones, ellas deben obedecer a, derivarse de, la función. social que debe cumplir la propiedad, y esta función, que no está definida en la Constitución, está a lo menos descrita en su alcance: comprende, dice el inciso segundo del № 24 "cuanto exijan los intereses generales de la Nación, 
la seguridad nacional, la utilidad pública, la salubridad pública y la conservación del patrimonio ambiental". Ninguna otra razón puede justificar la imposición de una limitación u obligación a la propiedad raíz urbana, y encuadrarla en alguna de las causales justificadas debe ser resultado de una razón lógica, indiscutible, fácilmente deducible, indudable, racional y prudente. Es de presumir que la utilidad y la salubridad públicas, como también la conservación del patrimonio ambiental, sean las causales más invocadas para que un Plan Regulador limite el uso y goce de la propiedad urbana, o le imponga alguna obligación, en función del uso del suelo, límites urbanos, densidad de urbanización y construcciones, pero no debemos olvidar que esta exigencia debe respetarse. Si no hay tales utilidad o salubridad públicas o conservación del patrimonio ambiental, $\mathbf{u}$ otro de los presupuestos constitucionales, aunque exista otra razón, la limitación u obligación devendrá ilícita.

Reafirmemos que la primera limitación que tiene la ley, para limitar el uso y goce de la propiedad, es no exagerar y llegar, de hecho, a una privación de tales uso y goce.

La segunda limitación la encontramos en el № 26 del artículo 19, el que nos asegura "que los preceptos legales que por mandato de la Constitución (y para qué decir aquellos que lo hacen sin ese mandato) regulen o complementen las garantías... o que las limiten en los casos en que ella lo autoriza, no podrán afectar los derechos en su esencia, ni imponer condiciones, tributos o requisitos que impidan su libre ejercicio". En el caso de la propiedad, la Constitución ordena a la ley establecer los modos de usarla y gozarla; además, la faculta para establecer limitaciones u obligaciones que deriven de su función social. Pues bien, la ley en cumplimiento del mandato recibido no podrá afectar el derecho de propiedad en su esencia, ni imponer condiciones o requisitos que impidan el libre ejercicio del derecho de propiedad. Si lo hace, la ley será inconstitucional.

Hay también una tercera limitación a la ley. No podrá "establecer diferencias arbitrarias", como se lo ordena específicamente a ella el № 2 del artículo $2^{\circ}$ y genéricamente a toda autoridad, cuando dice: "Ni la ley ni autoridad alguna podrán establecer diferencias arbitrarias". Esto significa la expresa prohibición de tratar en forma desigual a quienes son iguales, o de tratar por igual a quienes son distintos, entendido en forma racional, evitando

${ }^{1}$ Sin perjuicio, lo dicho, de que tales limitaciones son indemnizables, como lo han establecido variadas leyes (v.gr., 18.755, entre otras) y lo ha reconocido expresamente la Corte Suprema (vid. Galletué con Fisco, en RDJ t. 81 (1984) 2.5, 181-189). 
tratos caprichosos o inicuos. Puede el legislador dar tratos distintos, si hay causa racional y justa para hacerlo, lo que se prohíbe es dar el trato desigual movido por el capricho o la sola voluntad.

En sintesis, llamada la ley a establecer en materia de propiedad urbana el modo de usarla y gozarla, pudiendo imponerle limitaciones y obligaciones que deriven de su función social, está a su vez limitada por las siguientes exigencias constitucionales:

a) No puede llegar a una privación de los atributos o facultades esenciales del dominio;

b) No puede imponerle condiciones, tributos o requisitos que impidan el libre ejercicio del dominio, $y$

c) No puede establecer diferencias arbitrarias entre propiedades que sean iguales.

No en el № 24 que trata del derecho de propiedad, pero sí en el № 8 que trata del medio ambiente, el legislador ha recibido otro encargo genérico, que puede afectar el derecho de propiedad. Se trata de la autorización que la Constitución otorga a la ley para "establecer restricciones especificas al ejercicio de determinados derechos o libertades para proteger el medio ambiente". En uso de esta facultad, podrá entonces la ley establecer restricciones específicas (no genéricas) al ejercicio del derecho de propiedad. Situación que, como ya hemos visto, no es nueva para la propiedad, pues en el inciso $2^{\circ}$ del № 24 que ya hemos analizado, la ley ha recibido también el permiso de establecer limitaciones $u$ obligaciones que deriven de la función social de la propiedad, función que comprende, entre otras, la conservación del patrimonio ambiental. Esta ley, que sólo puede establecer restricciones específicas y no genéricas, deberá respetar también las mismas tres limitaciones que hemos señalado precedentemente: no afectar la esencia de la propiedad, no impedir su libre ejercicio y dar un trato igualitario, sin discriminaciones?.

\section{LA LEY GENERAL DE URBANISMO Y CONSTRUCCIONES}

Veamos, a continuación, en qué forma la Ley General de Urbanismo y Construcciones está cumpliendo los mandatos constitucionales de establecer

"Sobre "restricciones" vid. E. Soto Kloss, Derecho Administrativo. Bases fundamentales (2 voIs.). Edit. Jurídica de Chile. Santiago. 1996, II 91-95. 
el modo de usar y gozar de la propiedad urbana, de imponer limitaciones u obligaciones que deriven de su función social, pero sin afectar la esencia del derecho de propiedad, sin privar al propietario de sus facultades y atributos esenciales, sin imponerle condiciones, tributos o requisitos que impidan su libre ejercicio sin establecer diferencias arbitrarias, respetando, en general, los derechos que emanan de la naturaleza humana.

La primera Ley General de Urbanización sobre Construcciones se dictó en 1931, mediante el DFL № 345, después se dictó el DFL № 224, de 5 de agosto de 1953 y a continuación la Ley General de Urbanismo y Construcciones, DFL № 458 , de 13 de abril de 1976, todas, como puede observarse, anteriores a la Constitución de 1980.

Será dificil que en este trabajo analicemos todas las disposiciones de la Ley, por lo que elegiremos sólo algunos artículos que nos parecen más relevantes.

En términos generales, debemos reconocer que la Ley General de Urbanismo y Construcciones cumple su objetivo de normar la planificación urbana, la urbanización y construcción, con respeto a las normas y principios constitucionales, encontrando en su concepción global y en varias de sus disposiciones una especial preocupación por así hacerlo. Hay un propósito serio de buscar el bien común a través del ordenamiento urbano, que constituye hoy una de las condiciones materiales del ambiente en que se desenvuelve la sociedad, que hará posible a todos y a cada uno de sus integrantes alcanzar su realización material y espiritual. Sin embargo, que lo logre y que lo haga con pleno respeto de los derechos y garantías constitucionales, es lo que tratamos de establecer en este trabajo.

La ley es la norma general y obligatoria que debe estatuir las bases generales de un ordenamiento jurídico (artículo 60 № 20) y que en este caso está llamada por la propia Constitución para regular el uso y goce de la propiedad, pudiendo imponerle limitaciones y obligaciones derivadas de su función social (artículos 60 № 2 y 19 № 24). El Reglamento, expresión de la potestad del Presidente de la República, debe ser la norma que haga más cómoda y eficaz la ejecución de la ley (artículo 32 № 8 ).

Estamos en presencia de una norma general emanada del Poder Legislativo, en uno de los casos en que constitucionalmente puede dictarse una ley; de una norma menos general que puede dictar el Presidente de la República, respetando sí la norma general, y ambas respetando la Constitución. Más abajo las autoridades encargadas por la Ley y/o el Reglamento (llamado Ordenanza en este caso) que deben respetar la Ordenanza, la Ley y la Constitución. 
Considero útil dejar en claro que todo lo dicho respecto de la Ley, en este trabajo, relativo a sus facultades y límites, son aplicables por cierto a la Ordenanza y a las autoridades que intervengan. No podría ser de otro modo y entender que las normas inferiores, o quienes están llamadas a aplicarlas, queden exentas de las disposiciones constitucionales o de los límites legales. Así, por ejemplo, la obligación de respetar los derechos de las personas, o de dar un trato igualitario y no arbitrariamente discriminatorio, $o$ de no dañar el derecho de propiedad en su esencia o de no establecer requisitos que impidan su libre ejercicio, se aplican igual que a la ley, a la Ordenanza, a decretos o acuerdos municipales o de cualquier autoridad. propiedad urbana.

Dicho lo anterior, analicemos algunas normas legales sobre la

\section{USO DEL SUELO YCONSTRUCCIONES}

Los planes reguladores pueden disponer sobre el uso del suelo urbano y sobre las construcciones que se levanten en los terrenos concordantes con dicho propósito (artículo 57 de la Ley).

Aceptando que la ley puede establecer el uso y goce de la propiedad, lo que en definitiva se concretará en un acto administrativo regulado por la ley, como sería la dictación, aprobación o modificación de un Plan Regulador, nada podemos objetar a este artículo 57 , pero sí debemos exigirle a él y a la conducta de los órganos habilitados para aplicarlo que sean objetivos, dando un trato igualitario a los propietarios que estén en iguales condiciones y si imponen limitaciones, obligaciones, condiciones o requisitos, que ellos no afecten la esencia del derecho de propiedad y no impidan su libre ejercicio.

Debemos decir que la calificación del uso del suelo deberá obedecer a causas generales, racionales y objetivas, y no al capricho o mera voluntad de quienes aprueben un Plan, sin discriminar entre quienes estén en iguales condiciones. Permitir un uso del suelo distinto a quienes enfrenten una misma calle, porque unas propiedades se ubican en la acera oriente y no en la poniente, o en la sur y no en la norte, parece constituir una discriminación arbitraria fruto de la voluntad de sus autores, quienes disponen del valor de un bien afectando derechos de otra persona, por mero azar. Permitir la construcción en mayor o menor altura, con mayor o menor densidad, por la sola circunstancia de tener frente a una $u$ otra acera de una misma calle, o por estar a mayor o menor distancia de una 
esquina, no parece ser una causa racional, sino más bien caprichosa, porque ¿qué diferencia en su esencia una cosa de otra? fijar um metro más o menos, un grado más o menos, no altera la esencia sino el accidente, y ello sólo inspirado en la voluntad u opinión de una o más personas.

Se podrá responder que es necesario, en algún momento y en alguna medida, tomar una decisión y hacer una separación o límite. Estoy de acuerdo, pero si ello es fưto sólo del azar o de la voluntad, sin que exista una razón que diferencie a una propiedad de otra, en función de una cualidad importante y no banal, y con esa decisión se produce un trato desigual, que además trae consecuencias patrimoniales, su actuación estará viciada, pues la autoridad sólo podría imponer el uso, la limitación, condición o requisito que afectan la esencia del derecho, expropiando al afectado su facultad esencial del dominio con el pago de la correspondiente indemnización. Si no hay daño patrimonial y sólo se produce un efecto afectivo, simplemente deberá prevalecer la exigencia del bien común en cumplimiento de la función social de la propiedad, si hay un motivo de interés nacional, de utilidad pública o de conservación del patrimonio ambiental que lo exijan, por ejemplo, ya que la Constitución protege la propiedad sólo en su aspecto económico.

Toda fijación puede ser cuestionable, si acaso se causa daño a algunos propietarios sin indemnizarles el perjuicio. Por el contrario, la obligación de pagar puede convertirse en la pauta para que la autoridad sólo intervenga cuando la necesidad social sea tan exigente, que la propia comunidad esté dispuesta a soportar su costo.

Es necesaria, en consecuencia, una conciencia colectiva que sepa, que si priva a algunos de las facultades esenciales de su dominio, es con cargo al costo de los vecinos, del barrio o de la comuna, que se benefician con tal restricción o limitación.

Veamos también algunos casos específicos. El artículo 59 de la Ley declara de utilidad pública todos los terrenos consultados en el plan regulador comunal destinados a calles, plazas, parques u otros espacios de tránsito público en los cuales, y mientras se procede a su expropiación o adquisición, no podrá aumentarse el volumen de las construcciones existentes a la fecha de aprobación del plan regulador. Por su parte, el artículo 62 expresa que los terrenos cuyo uso no se conformare con el plan regulador se entenderán congelados, en el sentido de que no podrá aumentarse el volumen de construcción en ellos existentes, rehacer las instalaciones existentes, ni otorgarse patente a un nuevo propietario o arrendatario. El 121 dice que en los terrenos a que se refiere el artículo 59 no podrán efectuarse nuevas construcciones y si esturieren edificados, no sexá permitido reconstruir los 
edificios, alterarlos o repararlos (a menos que la Dirección de Obras Municipales lo autorice y siempre que el propietario renuncie a la eventual indemnización de perjuicios por esas nuevas obras, en caso de expropiación).

Todos los propietarios afectados por lo dispuesto en los artícu$\operatorname{los} 59,62$ y 121 a que me he referido precedentemente, ven limitados sus derechos de uso y goce de sus bienes. Unos no pueden aumentar el volumen de sus construcciones, otros no pueden rehacer las instalaciones existentes, otros no pueden efectuar nuevas construcciones, alterarlas o repararlas, otros no pueden obtener nuevas patentes comerciales, lo que significa no poder realizar legalmente una actividad económica. ¿Por cuánto tiempo?: "mientras se procede a su expropiación o adquisición". ¿Hay tiempo u obligación para ello? La respuesta es no.

Cabe preguntarse si esos propietarios están sólo viendo regulados o limitados sus derechos de uso y goce de sus propiedades, o están siendo privados de esas facultades esenciales del dominio, y viéndose impedidos de ejercer libremente su derecho por la imposición de condiciones o requisitos que la ley puede establecer, pero que está limitada para hacerlo precisamente por el Art. $19 \mathrm{~N}^{2}$ 26, de la Constitución. La sola circunstancia de que estas limitaciones sean indefinidas ya constituye una discriminación odiosa, carente de fundamentación en la razón y en la justicia, y una privación del derecho.

En 1978 se dictó el DL № 2.186, publicado en el Diario Oficial de 9 de junio, que aprueba la Ley Orgánica de Procedimientos de Expropiaciones, bajo la vigencia del Acta Constitucional $N^{\circ} 3$, de 1976. Su artículo $1^{\circ}$ dice así: "Toda expropiación por causa de utilidad pública o de interés social o nacional, cualquiera que sea la ley que la autorice o la institución que la decreta, se sujetará al procedimiento establecido en el presente texto". Su artículo $2^{2}$ permite a la entidad autorizada para expropiar, ordenar el estudio de la expropiación de un bien determinado, resolución que se publica en el Diario Oficial y cuyos efectos duran 90 días. Estos efectos constituyen una especie de congelación del bien.

El artículo 41 deroga todas las leyes preexistentes sobre las materias que en esta ley se tratan, aun en la parte que no le sean contrarias.

En consecuencia, además que las normas sobre congelación de la Ley General de Urbanismo y Construcciones pueden estar derogadas, es manifiesto el distinto trato que la legislación general da a las expropiaciones que la que otorga esa ley a la propiedad urbana.

El peso del bien común, necesario en cuanto a planificar la ciudad, a pensar en su crecimiento, a prevenir necesidades, con todo lo 
racional que se presenta, no debe recaer en uno o en unos pocos propietarios, como ya lo hemos dicho. Debe recaer en todos y si uno o unos pocos reciben un daño, deberán ser indemnizados del mismo, pues la acción del Estado en la búsqueda del bien común debe hacerse con pleno respeto de los derechos que emanan de la naturaleza humana.

Puede limitarse el ejercicio de un derecho, lo que entendemos en el espacio o en el tiempo, pero si es en todo el espacio o en todo el tiempo, la limitación se transforma en privación y ya hemos visto que, si hay privación debe haber expropiación e indemnización.

Entiendo el propósito de estas disposiciones: no hacer más oneroso para el Estado la expropiación o adquisición de estos bienes. Pero este propósito equivale a invertir la declaración constitucional de que el Estado se encuentra al servicio del hombre y transformarla en lo contrario, imponiendo al hombre el precio o costo de una obligación del Estado, lo que en los tiempos que corren, afortumadamente, es una aberración insostenible. Si el Estado no puede pagar a un propietario no debe, pues, causarle daño, ya que su acción debe respetar sus derechos. Ello no lleva a un inmovilismo, sino a un realismo honrado. Podrá conversar, negociar y llegar a un acuerdo conveniente, como cualquier persona, pudiendo sí imponer su potestad en cuanto la enajenación no será voluntaria sino forzada, pero las condiciones económicas deberán ser justas.

Hay demasiados casos en que la congelación es indefinida y los propietarios sufren las consecuencias, no porque dejen de ser propietarios, sino porque de hecho se ven privados del libre ejercicio de sus derechos, del íntegroy cabal uso y goce de sus propiedades, padeciendo condiciones y requisitos discriminatorios, que conllevan la privación de sus derechos, justamente lo que la Constitución no ha querido que suceda. Nuestros Tribunales no han querido discurrir en torno a esta nueva realidad constitucional, o los abogados no han sabido hacerlo, fruto de ignorancia, comodidad o inercia, pero es necesario que lo hagan y estas reflexiones quieren contribuir a que así sea.

Los artículos 51 letra c), 70 y 135 se refieren a la obligación que tienen los urbanizadores de terrenos de hacer cesiones gratuitas de calles,

${ }^{3}$ Hace excepción a lo dicho la causa Marin Palacios con Alcalde de la I. Municipalidad de Las Condes, de 17 de enero de 1995, Corte de Apelaciones de Santiago, comentada en Informe Constitucional № 1.002 , que esboza una teoría sobre la desvalorización de la propieclad. Ya antes, prevención del ministro Sr: Valenzuela Erazo en Jardín del Este, RDJ t. 88 (1991) 2. 5, 315-321, espec. $320 \mathrm{~s}$. 
plazas, áreas verdes y espacios comunitarios incluidos en la superficie urbanizada, que señale la Ordenanza General, es decir, el Reglamento de la Ley. Es una condición para el uso y goce de la propiedad agxícola que se transforma en urbana, que dependerá en su constitucionalidad de la prudencia con que se fijen los porcentajes de cesión, pero parece discutible y riesgoso que ella dependa sólo de un Reglamento y no de la ley.

El artículo 60 permite al plan regulador señalar los terrenos que por su especial naturaleza y ubicación no sean edificables. Estos terrenos no podrán subdiridirse y deberán mantenerse como rústicos.

Las mismas observaciones sobre el paso de una limitación a una verdadera privación de los derechos de uso y goce hechas a propósito de los artículos 59, 62 y 121, cabe formular a esta disposición.

No es que la Constitución en forma directa haya garantizado, dentro del derecho de propiedad, el valor de las propiedades, pues éste depende de diversos factores, particularmente de un libre mercado. Pero sin que un propietario haga algo, se exponga a un riesgo o ejecute un acto de mala administración, una decisión de un órgano del Estado que altere sustancialmente sus valores, no parece que sea una medida aceptable desde el punto de vista del Derecho. Más aún, si esa medida implica una privación de una facultad esencial del dominio, como son algunas que hemos analizado, o es fruto de una arbitrariedad, su inconstitucionalidad es manifiesta.

Las privaciones burdas o groseras de la propiedad de épocas pretéritas han dado paso a estas fórmulas nuevas y más sutiles, bajo la invocación del bien común o de la función social de la propiedad, que no podemos negar ni rechazar; pero cuya obtención no debe lograrse a un precio que sólo lo pague la víctima, ya que su pago corresponde a la comunidad toda".

${ }^{4}$ Como lo ha dicho repetidas veces la jurisprudencia (vid. Abalos con Fïsco, Lapostol con Fisco y Galletué con Fisco, en Soto Kloss cit., II, 385 ss.). 